Correction: c-MET receptor as potential biomarker and target molecule for malignant testicular germ cell tumors

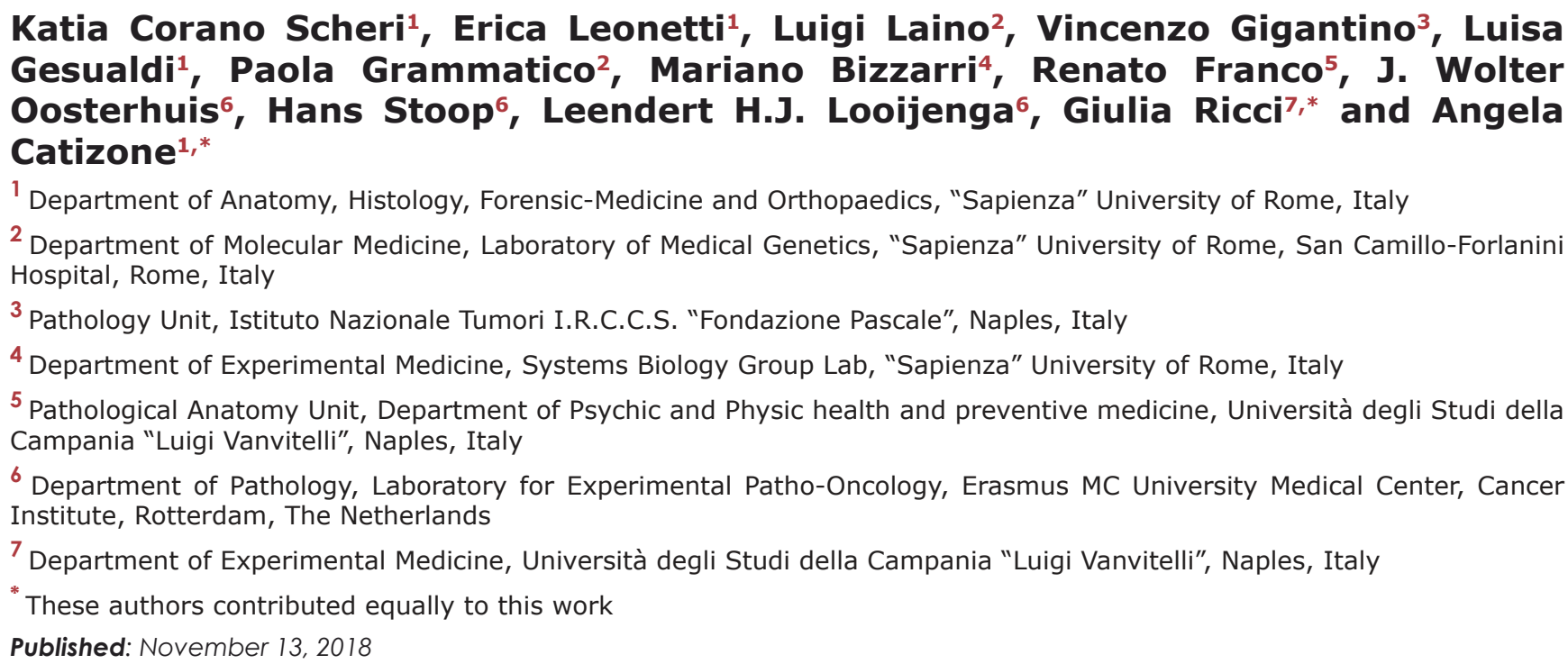
Gesualdi $^{1}$, Paola Grammatico ${ }^{2}$, Mariano Bizzarri ${ }^{4}$, Renato Franco5${ }^{5}$ J. Wolter Oosterhuis', Hans Stoop ${ }^{6}$, Leendert H.J. Looijenga6, Giulia Ricci ${ }^{7, *}$ and Angela Catizone $^{1, *}$

${ }^{1}$ Department of Anatomy, Histology, Forensic-Medicine and Orthopaedics, "Sapienza" University of Rome, Italy

2 Department of Molecular Medicine, Laboratory of Medical Genetics, "Sapienza" University of Rome, San Camillo-Forlanini Hospital, Rome, Italy

3 Pathology Unit, Istituto Nazionale Tumori I.R.C.C.S. "Fondazione Pascale", Naples, Italy

${ }^{4}$ Department of Experimental Medicine, Systems Biology Group Lab, "Sapienza" University of Rome, Italy

${ }^{5}$ Pathological Anatomy Unit, Department of Psychic and Physic health and preventive medicine, Università degli Studi della Campania "Luigi Vanvitelli", Naples, Italy

${ }^{6}$ Department of Pathology, Laboratory for Experimental Patho-Oncology, Erasmus MC University Medical Center, Cancer Institute, Rotterdam, The Netherlands

7 Department of Experimental Medicine, Università degli Studi della Campania "Luigi Vanvitelli", Naples, Italy

* These authors contributed equally to this work

Published: November 13, 2018

Copyright: Scheri et al. This is an open-access article distributed under the terms of the Creative Commons Attribution License 3.0 (CC BY 3.0), which permits unrestricted use, distribution, and reproduction in any medium, provided the original author and source are credited.

This article has been corrected: The correct author name is given below:

\title{
Mariano Bizzarri
}

Original article: Oncotarget. 2018; 9:31842-31860. https://doi.org/10.18632/oncotarget.25867 